\title{
Evaluasi Kesalahan Proyeksi Penduduk Tahun 2020 untuk Memproyeksikan Penduduk Tahun 2025 Provinsi Jawa Barat
}

\author{
Wildan*, Yayat Karyana \\ Universitas Islam Bandung, Indonesia. \\ *wildaan241@gmail.com, yayatkaryana@gmail.com
}

Prodi Statistika, Fakultas Matematika dan Ilmu Pengetahuan Alam,

\begin{abstract}
West Java Province is one of the largest provinces in Indonesia. Naturally, the population factor is one of the supports in terms of development. The confusion of a number of population data from various Ministries and Institutions become one of the causes of the non-optimal implementation of government policies. Therefore, this thesis will discuss the calculation of error evaluation population projections carried out using the projection method and projecting from the results of population projections to improve data accuracy which exists. The method used as a benchmark for calculating projections is mathematical method, component method and mixed method. The three methods this results in population projections for year $\mathrm{t}$ from the total population aspect, gender and age grouping. After the population projections are obtained, then see how much error the projection value is. In this problem, MALPE and MAPE are in charge of this projection error evaluation technique. There are 3 aspects that become a reference in the calculation of the projected evaluation, namely: other factors are fertility mortality and mobility. Assumption of fertility is measured from the numerical value birth age group (ASFR) and total fertility (TFR). Assumption of mortality what is seen is a table of 24 death levels, while the assumption of mobility or migration is seen from the ASNMR (Age Specific Net Migration Rate) number. Obtained the smallest error value by the MAPE technique is 5.4 in the component method that carried out by BPS and the projection results for West Java Province are 51,338,337 million souls with the component method.
\end{abstract}

Keywords: MALPE, MAPE, Mixed Method, Component Method.

\begin{abstract}
Abstrak. Provinsi Jawa Barat merupakan salah satu provinsi terbesar di Indonesia. Tentunya, dalam faktor penduduk menjadi salah satu penunjang dalam hal pembangunan. Kesimpangsiuran sejumlah data penduduk dari berbagai Kementerian dan Lembaga menjadi salah satu penyebab tidak optimalnya pelaksanaan kebijakan pemerintah. Oleh karena itu, skripsi ini akan dibahas mengenai perhitungan evaluasi kesalahan proyeksi penduduk yang dilakukan menggunakan metode proyeksi serta memproyeksikan dari hasil proyeksi penduduk guna memperbaiki keakuratan data yang ada. Metode yang digunakan sebagai tolak ukur menghitung proyeksi adalah metode matematik, metode komponen dan metode campuran. Ketiga metode tersebut menghasilkan proyeksi penduduk tahun ke $\mathrm{t}$ dari aspek total penduduk, jenis kelamin dan pengelompokan umur. Setelah proyeksi penduduk diperoleh, selanjutnya dilihat berapa besar kesalahan nilai proyeksi. Pada permasalahan ini, MALPE dan MAPE yang bertugas dalam teknik evaluasi kesalahan proyeksi ini. Terdapat 3 aspek yang menjadi acuan dalam perhitungan evaluasi proyeksi, antara lain fertilitas, mortalitas dan mobilitas. Asumsi fertalitas diukur dari nilai angka kelahiran kelompok umur (ASFR) dan total fertilitas (TFR). Asumsi mortalitas yang dilihat adalah tabel level kematian 24, sedangkan asumsi mobilitas atau migrasi dilihat dari angka ASNMR (Age Specific Net Migration Rate). Didapatkan nilai kesalahan terkecil oleh teknik MAPE sebesar 5,4 pada metode komponen yang dilakukan BPS dan hasil proyeksi untuk Provinsi Jawa Barat sebanyak 51.338.337 juta jiwa dengan metode komponen.
\end{abstract}

Kata Kunci: MALPE, MAPE, Metode Campuran, Metode Komponen. 


\section{A. Pendahuluan}

Proyeksi populasi pertama-tama dan terutama dinilai dari keakuratannya (Yokum \& Armstrong, 1995). MALPE atau (Mean Algebratic Percent Error) dan MAPE atau (Mean Absolute Percent Error) merupakan dua metode yang sangat dibutuhkan ketika memeriksa kesalahan guna melakukan evaluasi proyeksi penduduk pada tahun tertentu. Kedua metode tersebut merupakan penopang asumsi keakuratan ketika menghitung proyeksi dan digunakan untuk evaluasi kesalahan proyeksi penduduk.

Nilai MALPE dan MAPE didapatkan, apabila beberapa aspek penunjang dari proyeksi terpenuhi. Diantaranya mencari jumlah total penduduk berdasarkan kelompok umur menggunakan metode matematik, metode komponen dan metode campuran. Ketiga metode tersebut berperan dalam perhitungan kesalahan dari proyeksi penduduk yang akan dicari. Hasil yang didapat, akan dijadikan bahan evaluasi proyeksi dan mengetahui metode mana yang paling mendekati keakuratan proyeksinya. Namun dalam penelitian ini, hanya berfokus kepada metode komponen dan metode campuran. Kemudian untuk evaluasi nilai kesalahan yang paling sedikit nilainya akan dijadikan tolak ukur untuk metode terbaik yang digunakan sebagai proyeksi penduduk selanjutnya. Pada studi kasus ini, penulis ingin mengetahui berapa besar nilai kesalahan proyeksi penduduk Jawa Barat tahun 2020 dan proyeksi penduduk Jawa Barat untuk tahun 2025.

BPS dalam publikasinya menerbitkan hasil Sensus Penduduk tahun 2020. Provinsi Jawa Barat menjadi acuan data utuk perhitungan evaluasi kesalahan dalam penulisan tugas akhir ini. Provinsi Jawa Barat tercatat sebanyak 48,7 juta jiwa dari total penduduk Indonesia yang tercatat sebanyak 270,28 juta jiwa. Jika dibandingkan dengan Sensus Penduduk tahun 2010, angka Provinsi Jawa Barat ini mengalami kenaikan sebanyak 5,2 juta jiwa.

Berdasarkan latar belakang yang telah diuraikan, maka perumusan masalah dalam penelitian ini sebagai berikut: "Bagaimana hasil evaluasi nilai kesalahan proyeksi Sensus Penduduk tahun 2020?" dan "Bagaimana proyeksi penduduk untuk tahun 2025 untuk Provinsi Jawa Barat?". Selanjutnya, tujuan dalam penelitian ini diuraikan dalam pokok-pokok sbb.

1. Mendapatkan nilai kesalahan evaluasi dari proyeksi penduduk 2020, dan

2. Melakukan proyeksi penduduknya untuk tahun 2025 Provinsi Jawa Barat.

\section{B. Metodologi Penelitian}

Data penelitian yang digunakan adalah data sekunder yang didapat dari hasil Sensus Penduduk 2020 Provinsi Jawa Barat, tabel kematian level 25, TFR sebesar 2,18 dan angka migrasi BPS tahun 2015. Kemudian data yang dihasilkan dari peneliti terdahulu dengan menghitung proyeksi penduduk tahun 2020 dengan menggunakan metode komponen dan campuran yang kemudian hasilnya salah satu metode tersebut akan dijadikan sebagai tolak ukur menghitung proyeksi penduduk tahun 2025 Provinsi Jawa Barat.

Apabila metode komponen yang terpilih maka untuk metode rumus proyeksi yang digunakan adalah:

$$
\mathrm{P}(\mathrm{x}, \mathrm{t}, \mathrm{k})=\mathrm{P}(\mathrm{x}, \mathrm{a})-\mathrm{D}(\mathrm{x})+\mathrm{NM}(\mathrm{x})
$$

Dimana: $\mathrm{P}(\mathrm{x}, \mathrm{a})$ merupakan penduduk tahun awal, $\mathrm{D}(\mathrm{x})$ merupakan banyaknya kematian dan $\operatorname{NM}(\mathrm{x})$ merupakan net migran. Untuk memenuhi metode komponen ini, diperlukan beberapa aspek yang harus diperhatikan, yaitu: 1. Data penduduk pada tahun dasar menurut kelompok umur dan jenis kelamin. Data dasar yang digunakan ini biasanya data dari Sensus Penduduk, hasil Survey Antar Sensus (SUSENAS) dan data tersebut sudah dilakukan prorating. 2. Tingkat kematian atau level of mortality (level tabel kematian). 3. Asumsi pola fertilitas yaitu ASFR (Age Specific Fertility Rate). 4. Rasio jenis kelamin saat lahir (sex ratio at birth). 5. Asumsi pola migrasi, dengan diperoleh nilai ASOMR dan ASIMR atau ASNMR.

Apabila metode campuran yang terpilih maka untuk rumus proyeksi yang digunakan adalah:

$$
\mathrm{P}(\mathrm{x}, \mathrm{t}, \mathrm{c})=\mathrm{V}(\mathrm{x}, \mathrm{t}, \mathrm{k}) \mathrm{P}(., \mathrm{t}, \mathrm{m})
$$

Dimana $\mathrm{V}(\mathrm{x}, \mathrm{t}, \mathrm{c})$ merupakan proyeksi proporsi metode komponen dan $\mathrm{P}(., \mathrm{t}, \mathrm{m})$ merupakan proyeksi dari metode matematik. 
Kemudian untuk menghitung nilai kesalahan yang akan dievaluasi, didapatkan dari hasil MALPE dan MAPE. Dimana untuk MALPE rumusnya:

$$
M A L P E=\frac{\sum F_{t}}{n}
$$

dan nilai MAPE didapat dari rumus:

$$
M A P E=\frac{\sum\left|F_{t}\right|}{n}
$$

Dimana Ft merupakan nilai persentase kesalahan yang didapatkan dari selisih data proyeksi penduduk dengan data penduduk aktual pada tahun tertentu dibagi dengan data penduduk aktual dikali dengan 100 .

\section{Hasil Penelitian dan Pembahasan}

Evaluasi nilai kesalahan pada proyeksi penduduk tahun 2020 Provinsi Jawa Barat

Berikut adalah nilai kesalahan dari dua metode yang melakukan proyeksi penduduk Jawa Barat pada tahun 2020, dengan data proyeksi yang menggunakan data dasar yang sama yaitu SUPAS 2015 dihasilkan nilai kesalahan untuk MALPE didapatkan:

Nilai MALPE dari metode komponen didapatkan:

$$
\begin{aligned}
& \mathrm{n}=16 \\
& \Sigma \mathrm{F}_{\mathrm{t}}=84,0 \\
& \text { MALPE }=\frac{\sum \mathrm{F}_{\mathrm{t}}}{\mathrm{n}}=\frac{84,0}{16}=5,3
\end{aligned}
$$

Nilai MALPE dari metode campuran didapatkan:

$$
\begin{aligned}
& \mathrm{n}=16 \\
& \Sigma \mathrm{F}_{\mathrm{t}}=33,7 \\
& \text { MALPE }=\frac{\sum \mathrm{F}_{\mathrm{t}}}{\mathrm{n}}=\frac{84,0}{16}=2,1
\end{aligned}
$$

Kemudian untuk nilai MAPE didapatkan:

Nilai MAPE untuk metode komponen yang dilakukan BPS tahun 2018, didapatkan:

$$
\begin{aligned}
& n=16 \\
& \left|\Sigma F_{t}\right|=86,4 \\
& \text { MAPE }=\frac{\sum\left|F_{t}\right|}{n}=\frac{86,4}{16}=5,4
\end{aligned}
$$

Nilai MAPE untuk metode campuran yang dilakukan Karyana tahun 2017, didapatkan:

$$
\begin{aligned}
& \mathrm{n}=16 \\
& \left|\Sigma \mathrm{F}_{\mathrm{t}}\right|=125,6 \\
& \text { MAPE }=\frac{\sum\left|\mathrm{F}_{\mathrm{t}}\right|}{\mathrm{n}}=\frac{125,6}{16}=7,8
\end{aligned}
$$

Proyeksi Penduduk tahun 2025 Provinsi Jawa Barat dengan menggunakan metode komponen

Hasil yang didapat dari teknik kesalahan MAPE, bahwa metode komponen yang dianggap mendek ati keakuratan dengan data aktual sehingga digunakan untuk memproyeksikan penduduk tahun 2025.

Untuk menghasilkan proyeksi penduduk dengan metode ini, dibutuhkan tabel proyeksi penduduk berdasarkan jenis kelamin dan total keseluruhan berdasar asumsi-asumsi yang menjadi penunjang metode komponen ini.

Tabel proyeksi metode komponen pada jenis kelamin perempuan

Tabel 1. Hasil Perhitungan Proyeksi Penduduk Perempuan Tahun 2025 Provinsi Jawa Barat

\begin{tabular}{|c|c|c|c|c|c|c|c|c|c|}
\hline $\mathrm{X}$ & $\begin{array}{c}\text { Pend } \\
2020\end{array}$ & RMH & $\begin{array}{c}\text { P hidup } \\
2025\end{array}$ & $\begin{array}{c}\text { Rata-rata } \\
\text { Pddk }\end{array}$ & $\begin{array}{c}\text { ASF } \\
\text { R }\end{array}$ & $\begin{array}{c}\text { Kelahir } \\
\text { an }\end{array}$ & $\begin{array}{c}\text { ASN } \\
\text { MR }\end{array}$ & Mgnet & $\begin{array}{c}\text { Pddk } \\
2025\end{array}$ \\
\hline $\mathbf{1}$ & $\mathbf{2}$ & $\mathbf{3}$ & $\mathbf{4}$ & $\mathbf{5}$ & $*$ & $* *$ & $\mathbf{6}$ & $\mathbf{7}$ & $\mathbf{8}$ \\
\hline
\end{tabular}


Evaluasi Kesalahan Proyeksi Penduduk Tahun 2020 untuk Memproyeksikan... | 95

\begin{tabular}{|c|c|c|c|c|c|c|c|c|c|}
\hline $\begin{array}{c}0- \\
4\end{array}$ & $\begin{array}{c}191051 \\
4\end{array}$ & $\begin{array}{c}0,9986 \\
7\end{array}$ & 2059450 & 1984982 & & & 1,06 & 2104 & $\begin{array}{c}206155 \\
4\end{array}$ \\
\hline 5 & $\begin{array}{c}188290 \\
4\end{array}$ & $\begin{array}{c}0,9994 \\
6\end{array}$ & 1907973 & 1895439 & & & $-0,2$ & -379 & $\begin{array}{c}190759 \\
4\end{array}$ \\
\hline 10 & $\begin{array}{c}195441 \\
5\end{array}$ & $\begin{array}{c}0,9992 \\
8\end{array}$ & 1881887 & 1918151 & & & $-0,08$ & -153 & $\begin{array}{c}188173 \\
4\end{array}$ \\
\hline 15 & $\begin{array}{c}197584 \\
4\end{array}$ & $\begin{array}{c}0,9988 \\
9\end{array}$ & 1953008 & 1964426 & $\begin{array}{c}0,03 \\
9\end{array}$ & 77224 & 1,01 & 1984 & $\begin{array}{c}195499 \\
2\end{array}$ \\
\hline 20 & $\begin{array}{c}200500 \\
5\end{array}$ & $\begin{array}{c}0,9985 \\
4\end{array}$ & 1973651 & 1989328 & $\begin{array}{c}0,10 \\
3\end{array}$ & 204395 & 0,62 & 1233 & $\begin{array}{c}197488 \\
4\end{array}$ \\
\hline 25 & $\begin{array}{c}198541 \\
6\end{array}$ & $\begin{array}{c}0,9981 \\
2\end{array}$ & 2002078 & 1993747 & $\begin{array}{c}0,11 \\
4\end{array}$ & 228006 & 3,71 & 7397 & $\begin{array}{c}200947 \\
4\end{array}$ \\
\hline 30 & $\begin{array}{c}196281 \\
1 \\
\end{array}$ & $\begin{array}{c}0,9972 \\
8 \\
\end{array}$ & 1981683 & 1972247 & $\begin{array}{c}0,09 \\
4\end{array}$ & 185019 & 1,98 & 3905 & $\begin{array}{c}198558 \\
8 \\
\end{array}$ \\
\hline 35 & $\begin{array}{c}188000 \\
4\end{array}$ & $\begin{array}{c}0,9956 \\
9 \\
\end{array}$ & 1957472 & 1918738 & $\begin{array}{c}0,05 \\
8\end{array}$ & 111428 & 1,12 & 2149 & $\begin{array}{c}195962 \\
1 \\
\end{array}$ \\
\hline 40 & $\begin{array}{c}180055 \\
1\end{array}$ & $\begin{array}{c}0,9925 \\
9\end{array}$ & 1871901 & 1836226 & $\begin{array}{c}0,02 \\
1\end{array}$ & 39374 & 0,66 & 1212 & $\begin{array}{c}187311 \\
3\end{array}$ \\
\hline 45 & $\begin{array}{c}161924 \\
3\end{array}$ & $\begin{array}{c}0,9874 \\
9\end{array}$ & 1787209 & 1703226 & $\begin{array}{c}0,00 \\
6\end{array}$ & 10652 & 1,07 & 1822 & $\begin{array}{c}178903 \\
1\end{array}$ \\
\hline 50 & $\begin{array}{c}139545 \\
3\end{array}$ & $\begin{array}{c}0,9800 \\
9\end{array}$ & 1598986 & 1497220 & & & 0,71 & 1063 & $\begin{array}{c}160004 \\
9\end{array}$ \\
\hline 55 & $\begin{array}{c}114800 \\
8\end{array}$ & $\begin{array}{c}0,9669 \\
4\end{array}$ & 1367670 & 1257839 & & & 0,95 & 1195 & $\begin{array}{c}136886 \\
4\end{array}$ \\
\hline 60 & 869440 & 0,9406 & 1110055 & 989747 & & & 0,66 & 653 & $\begin{array}{c}111070 \\
8\end{array}$ \\
\hline 65 & 627519 & $\begin{array}{c}0,8884 \\
5\end{array}$ & 817795 & 722657 & & & 1,17 & 846 & 818641 \\
\hline 70 & 382733 & $\begin{array}{c}0,7981 \\
9\end{array}$ & 557519 & 470126 & & & 0,62 & 291 & 557811 \\
\hline $\begin{array}{c}75 \\
+ \\
\end{array}$ & 365417 & 0,5397 & 502709 & 434063 & & & $-0,11$ & -48 & 502661 \\
\hline Jml & $\begin{array}{c}237652 \\
77\end{array}$ & $\begin{array}{c}15,079 \\
98\end{array}$ & $\begin{array}{c}25331046 \\
, 79\end{array}$ & $\begin{array}{c}24548161, \\
89\end{array}$ & $\begin{array}{c}0,43 \\
6\end{array}$ & 856099 & 14,95 & $\begin{array}{c}25274 \\
64\end{array}$ & $\begin{array}{c}253563 \\
21\end{array}$ \\
\hline
\end{tabular}

Tabel 2. Hasil Perhitungan Proyeksi Penduduk Laki-laki Tahun 2025 Provinsi Jawa Barat

\begin{tabular}{|l|l|l|l|l|l|l|l|}
\hline $\mathrm{X}$ & Pend 2020 & RMH & P hidup 2025 & Rata-rata Pddk & ASNMR & MigNet & Pddk 2025 \\
\hline $\mathbf{1}$ & $\mathbf{2}$ & $\mathbf{3}$ & $\mathbf{4}$ & $\mathbf{5}$ & $\mathbf{6}$ & $\mathbf{7}$ & $\mathbf{8}$ \\
\hline $0-4$ & 2004029 & 0,99851 & 2151333 & 2077681 & 1,06 & 2202 & 2153535 \\
\hline 5 & 1971043 & 0,99889 & 2001043 & 1986043 & 0,91 & 1807 & 2002850 \\
\hline 10 & 2081654 & 0,99804 & 1968855 & 2025255 & 0,44 & 891 & 1969746 \\
\hline 15 & 2099794 & 0,99674 & 2077574 & 2088684 & 0,77 & 1608 & 2079182 \\
\hline 20 & 2114652 & 0,99613 & 2092949 & 2103800 & 4,17 & 8773 & 2101722 \\
\hline 25 & 2072445 & 0,99589 & 2106468 & 2089457 & 2,98 & 6227 & 2112695 \\
\hline 30 & 2017305 & 0,99511 & 2063927 & 2040616 & 1,99 & 4061 & 2067988 \\
\hline 35 & 1913734 & 0,99294 & 2007440 & 1960587 & 0,97 & 1902 & 2009342 \\
\hline 40 & 1810993 & 0,98779 & 1900223 & 1855608 & 0,53 & 983 & 1901207 \\
\hline 45 & 1626660 & 0,97692 & 1788881 & 1707770 & 1,06 & 1810 & 1790691 \\
\hline 50 & 1411753 & 0,95863 & 1589117 & 1500435 & 0,38 & 570 & 1589687 \\
\hline 55 & 1166608 & 0,93224 & 1353349 & 1259978 & 0,12 & 151 & 1353500 \\
\hline 60 & 895701 & 0,89387 & 1087559 & 991630 & 0,67 & 664 & 1088223 \\
\hline 65 & 641447 & 0,83198 & 800640 & 721044 & 1,17 & 844 & 801484 \\
\hline
\end{tabular}




\begin{tabular}{|l|l|l|l|l|l|l|l|}
70 & 373852 & 0,73674 & 533671 & 453762 & 0,74 & 336 & 534007 \\
\hline $75+$ & 307215 & 0,49020 & 426029 & 366622 & 0,35 & 128 & 426157 \\
\hline Jml & 24508885 & 14,78062 & 25949057 & 25228971 & 18,31 & 32958 & $\mathbf{2 5 9 8 2 0 1 5}$ \\
\hline
\end{tabular}

1. Kolom (1) merupakan kelompok umur dalam interval 5 tahun.

2. Kolom (2) merupakan hasil sensus penduduk 2020 per kelompok perempuan/laki-laki Provinsi Jawa Barat yang didapatkan dari BPS. Dari tabel didapatkan total penduduk perempuan pada tahun 2020 menurut SP adalah 23.765.277 juta jiwa.

3. Kolom (3) merupakan nilai Rasio Masih Hidup (RMH) atau mortalitas Provinsi Jawa Barat yang diambil dari nilai tabel kematian level 24. Artinya, sebanyak sekian persen penduduk yang masih hidup.

4. Kolom (4) merupakan penduduk yang diharapkan hidup pada saat tahun 2025. Khusus untuk penduduk 0-4 tahun, digunakan rumus Pddk Hidup $(0)=5 \mathrm{x}$ jumlah kelahiran $\mathrm{x}$ sex ratio $\mathrm{x}_{0}$ dan contohnya untuk kelompok perempuan didapatkan sebanyak 2.059.450 juta jiwa. Kemudian untuk kolom selanjutnya merupakan angka masih hidup dari umur tepat $\mathrm{x}$ tahun hingga umur tepat $\mathrm{x}+\mathrm{n}$. Dari rumus Pddk Hidup $(\mathrm{x})=\mathrm{P}(\mathrm{x}, \mathrm{a}) \mathrm{x}\left(\mathrm{S}_{\mathrm{x}}\right)$ hasilnya didapat sebanyak 1.907.973 juta jiwa dan seterusnya sampai dengan umur $75+$.

5. Kolom (5) merupakan rata-rata penduduk yang diambil dari penjumlahan kolom (2) dengan kolom (4) dibagi 2. Contohnya untuk kelompok umur $0-4$ tahun perempuan adalah $1.910 .514+2.059 .450 / 2=1.984 .982$. Artinya, sebanyak 1.984 .982 juta jiwa merupakan rata-rata penduduk antara tahun 2020 - 2025 untuk kelompok umur $0-4$ tahun.

6. Kolom (*) untuk tabel proyeksi perempuan merupakan nilai ASFR yang didapatkan dari hasil rumus $\mathrm{ASFR}_{\mathrm{u}}=\frac{\mathrm{B}_{\mathrm{u}}}{\mathrm{P}_{\mathrm{u}}^{\mathrm{f}}}$ ? $\mathrm{k}$ dimana Bu merupakan jumlah kelahiran dan Pu jumlah perempuan yang berada dalam usia subur pada waktu tertentu per 1000 penduduk. Dihasilkan menghasilkan nilai TFR dengan rumus $T F R=5 \sum A S F R_{u}$. Sehingga didapatkan untuk $\sum \mathrm{ASFR}_{\mathrm{x}}=0,436$ dan nilai $\mathrm{TFR}=5$ $\sum \operatorname{ASFR}_{\mathrm{x}}=2,18$. Artinya, sebesar 2,18 rata-rata penduduk perempuan Jawa Barat akan mempunyai 2,18 anak selama masa usia subur (15 - 49 tahun).

7. Kolom (**) merupakan hasil kelahiran yang didapatkan. Kolom 7 didapat dari hasil perkalian rata-rata penduduk dikali dengan ASFR pada masa usia subur. Sehingga didapatkan sebanyak 856.099 total kelahiran per tahunnya di Provinsi Jawa Barat.

8. Kolom (6) merupakan angka migrasi neto penduduk perempuan berdasar kelompok umur yang diperoleh menggunakan rumus ASNMR $=\frac{\mathrm{Mi}_{\mathrm{u}}-\mathrm{Mo}_{\mathrm{u}}}{\mathrm{P}_{\mathrm{u}}} \mathrm{k}$, artinya mencari selisih antara migran masuk dan keluar dibagi jumlah penduduk per 1000 jiwa. Pada kolom ini, didapatkan nilai ASNMR per kelompok umur dari data BPS tahun 2015.

9. Kolom (7) merupakan migrasi neto penduduk perempuan berdasarkan kelompok umur. Nilai ini didapat dari perkalian antara ASNMR dengan rata-rata penduduk pada tahun tertentu per 1000 penduduk. Dengan menggunakan rumus $\mathrm{NM}(\mathrm{x})=\{\operatorname{ASOMR}(\mathrm{x})-$ $\operatorname{ASIMR}(\mathrm{x})\} \mathrm{P}(\mathrm{x}, \mathrm{a})$ untuk kelompok umur $0-4$ perempuan migran net nya adalah $(1,06$ $\mathrm{x} 1,984,982) / 1000=2104$. Artinya, sebanyak 2104 total migrasi neto umur $0-4$ tahun di Provinsi Jawa Barat.

10. Kolom (8) merupakan hasil akhir yang didapatkan untuk mencapai jumlah proyeksi penduduk perempuan Jawa Barat pada tahun 2025. Pada Persamaan (1) untuk mencari proyeksi pendudu dengan metode komponen contohnya untuk kelompok perempuan didapatkan total sebanyak 25.356.321 juta jiwa. Artinya, sebanyak 25.356.321 juta jiwa penduduk Jawa Barat diproyeksikan pada tahun 2025. 
Tabel 3. Hasil Perhitungan Total Proyeksi Penduduk Tahun 2025 Provinsi Jawa Barat

\begin{tabular}{|c|c|c|c|}
\hline$X$ & Pddk 2025 (P) & Pddk 2025 (L) & Total Proyeksi 2025 \\
\hline $0-4$ & 2061554 & 2153534,903 & 4215089 \\
\hline 5 & 1907594 & 2002850,296 & 3910444 \\
\hline 10 & 1881734 & 1969746,254 & 3851480 \\
\hline 15 & 1954992 & 2079182,245 & 4034174 \\
\hline 20 & 1974884 & 2101721,519 & 4076606 \\
\hline 25 & 2009474 & 2112694,878 & 4122169 \\
\hline 30 & 1985588 & 2067988,077 & 4053577 \\
\hline 35 & 1959621 & 2009342,148 & 3968963 \\
\hline 40 & 1873113 & 1901206,51 & 3774320 \\
\hline 45 & 1789031 & 1790691,012 & 3579722 \\
\hline 50 & 1600049 & 1589686,852 & 3189736 \\
\hline 55 & 1368864 & 1353499,976 & 2722364 \\
\hline 60 & 1110708 & 1088223,034 & 2198931 \\
\hline 65 & 818641 & 801483,8739 & 1620125 \\
\hline 70 & 557811 & 534006,8586 & 1091818 \\
\hline $75+$ & 502661 & 426156,8331 & 928818 \\
\hline Jml & & 25982015,27 & $\mathbf{5 1 3 3 8 3 3 7}$ \\
\hline
\end{tabular}

\section{Kesimpulan}

Berdasarkan pembahasan dalam penelitian ini, peneliti menyimpulkan beberapa hasil penelitian sebagai berikut:

1. Nilai kesalahan menggunakan teknik MALPE, besarnya rata-rata kesalahan untuk masing-masing metode sebesar 5,3 untuk metode komponen yang dilakukan BPS dan sebesar 2,1 untuk metode campuran yang dilakukan Karyana.

Selanjutnya, didapatkan nilai rata-rata kesalahan menggunakan teknik MAPE agar lebih mendekati keakurataan, besarnya rata-rata kesalahan absolut untuk masing masing metode sebesar 5,4 untuk metode komponen BPS dan 7,8 untuk metode campuran yang dilakukan Karyana. Pada akhirnya, metode komponen yang terpilih sebagai metode yang paling mendekati keakuratan untuk memproyeksikan penduduk Jawa Barat tahun 2025, karena nilai MAPE yang lebih sedikit.

2. Total Proyeksi penduduk dengan menggunakan metode komponen beserta asumsi TFR $=2,18$, tabel kematian level 24 dan angka migrasi tahun 2015 untuk Provinsi Jawa Barat didapat sebanyak 25.356 .321 untuk kelompok perempuan dan sebanyak 25.982.015 untuk kelompok umur laki-laki. Sehingga total untuk proyeksi penduduk tahun 2025 Provinsi Jawa Barat sebanyak 51.338.337 juta jiwa.

\section{Acknowledge}

Sungguh kebesaran Allah memang ada. Saya sangat berterimakasih kepada Allah SWT atas waktu dan nikmat yang diberikan sehingga saya bias menyelesaikan penelitian ini dengan baik, terlebih saya ingin mendedikasikan rasa terimakasih kepada diri saya pribadi yang sudah berjuang, orang tua dan teman-teman yang senantiasa memberikan support yang lebih.

\section{Daftar Pustaka}

[1] Alkema, L., Raftery, A. E., Gerland, P., Clark, S. J., Pelletier, F., Buettner, T., \& Heilig, G. K. (2011). Probabilistic Projections of the Total Fertility Rate for All Countries. Springer, 48:815-839.

[2] BPS. (2018). Proyeksi Penduduk Indonesia Tahun 2015-2045. Jakarta: BPS RI. 
[3] BPS. (2020). Potret Sensus Penduduk Provinsi Jawa Barat . Bandung: BPS.

[4] Junaidi. (2015). Model-model Proyeksi. Research Gate, 1-7.

[5] Karyana, Y. (2002). Proyeksi Penduduk Dengan Metoda Campuran. Berkala Ilmiah MIPA, $36-46$.

[6] Karyana, Y. (2009). Matematika Demografi. Bandung: Universitas Islam Bandung Program Studi Statistika.

[7] Karyana, Y. (2017). Proyeksi Penduduk Jawa Barat Tahun 2020-2030 dengan Data SUPAS 2015. Seminar Nasional FMIPA 2017 (p. 120). Sumedang: Universitas Padjajaran.

[8] Klosterman, R. E. (1990). Community analysis and planning techniques. Savage, Md. : Rowman \& Littlefield, c1990.

[9] Munir, R. (2011). Dasar-dasar Demografi.Ed. Selemba Empat dan Lembaga Demografi Fakultas Ekonomi Universitas Indonesia, 133-153.

[10] Nations, U. (1956). Methods for population Projections by Sex and Age. New York: Manual III.

[11] Utomo, B. (1985). Mortalitas:Pengertian dan contoh kasus di Indonesia. Jakarta: Universitas Indonesia.

[12] Yokum, J. T., \& Amstrong, J. S. (1995). Di luar akurasi : Perbandingan kriteria yang digunakan untuk memilih metode peramalan. Jurnal Peramalan Internasional, 591-597. 